\title{
As marcas de aprendizagem por meio da pesquisa, da escrita e da leitura de livros de divulgação científica: uma possibilidade para a sala de aula
}

Anelise Grünfeld de Luca

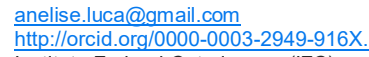
http://orcid.org/0000-0003-2949-916X Araquari, Santa Catarina, Brasil

\section{Sandra Aparecida dos Santos} esasandra@unidavi.edu.br http://orcid.org/0000-0003-2827-6300 Centro Universitário do Alto Vale do Itajaí (UNIDAVI), Rio do Sul, Santa Catarina, Brasil

José Claudio Del Pino delpinojc@yahoo.com.br http://orcid.org/0000-0002-8321-9774 Universidade Federal do Rio Grande do Sul (UFRGS), Porto Alegre, Rio Grande do Sul, Brasil

\section{Michelle Câmara Pizzato} michelle.pizzato@poa.ifrs.edu.br $\frac{\text { http://orcid.org/0000-0002-3394-1179. }}{\text { Instituto Federal do Rio Grande do Sul }}$ (IFRS), Porto Alegre, Rio Grande do Sul, Brasil

\section{RESUMO}

O presente trabalho apresenta as práticas de leitura realizadas no decorrer de quatro anos com 23 estudantes, entre os anos letivos de 2014 e 2017. Ao longo do Ensino Médio, a esses mesmos estudantes foram sendo apresentadas leituras diferentes, com estratégias didáticas diferentes. Logo após as leituras propostas foram privilegiadas as seguintes estratégias didáticas: rodas de conversas, registros individuais por meio de diários de leitura; apresentação de seminários, elaboração e realização de experimentos, representação de imagens (desenhos ou colagens) e representação teatral. Em 2017, os estudantes que se encontravam no 3 ㅇ ano do Ensino Médio, foram questionados quanto às memórias/marcas de aprendizagem deixadas pelas práticas de leituras, por meio de um questionário aberto. A partir das respostas dos estudantes foi possível articular duas categorias de análise: marcas de aprendizagem conceitual e dinâmicas de pesquisa. As leituras propostas proporcionaram marcas de aprendizagem evidenciadas pelos estudantes e dinamizaram as pesquisas posteriores, desenvolvidas no decorrer das aulas curriculares, possibilitando aprofundamento e ampliação dos conhecimentos e olhares mais pontuais para os conteúdos conceituais das ciências. Nesse processo as ações propostas pelo professor, no que tange o ensinar e o aprender das habilidades de leitura, individual e coletiva, e de escrita, expressam a relevância dessas práticas em sala de aula.

PALAVRAS-CHAVE: Prática de Leitura. Escrita. Pesquisa. Livros de divulgação científica. 


\section{INTRODUÇÃO}

Entre as características importantes para a Educação Básica Nacional, em particular para o ensino na área das Ciências da Natureza, estão a contextualização e a interdisciplinaridade, propostas nas Diretrizes Curriculares Nacionais Gerais para a Educação Básica (Resolução no4, de 13 de julho de 2010), que elucidam em seu Art. 17, § 2으, "A interdisciplinaridade e a contextualização devem assegurar a transversalidade do conhecimento de diferentes disciplinas e eixos temáticos, perpassando todo o currículo e propiciando a interlocução entre os saberes e os diferentes campos do conhecimento".

Considerando a contextualização e a interdisciplinaridade princípios condutores da organização curricular, ratificadas nas Diretrizes Curriculares Nacionais para o Ensino Médio, é possível constatar que, apesar de as ciências fazerem parte do dia a dia da população, o ensino das mesmas encontra-se tão distanciado da realidade que não permite aos estudantes a percepção do vínculo estreito entre o que é estudado nas disciplinas e o cotidiano.

Desde o texto preliminar da Base Nacional Comum Curricular - BNCC até sua 3a versão, todos apontam a importância da contextualização e da interdisciplinaridade quando apresentam cada um dos níveis de ensino da Educação Básica, em particular do Ensino Médio. Na área específica das Ciências da Natureza, é proposta uma organização dos conhecimentos em eixos que estruturarão o currículo e possibilitarão a articulação entre os componentes curriculares.

As ideias que emergem dos documentos oficiais da educação nacional, em particular da área das Ciências da Natureza, propõem uma prática voltada para a realidade, que capacite os estudantes a agirem no mundo de modo a transformálo e transformá-lo para melhor. No entanto, os próprios documentos apontam, assim como pesquisas específicas, que as práticas pedagógicas exercidas no chão das salas de aula continuam sendo transmissivas, pautadas na memorização, lineares, espontaneístas, essencialmente positivistas (GALIAZZI, 2003; RAMOS, 2012; MORAES, 2012; SCHWARTZ, 2012).

Inúmeros aspectos contribuem para a manutenção do ensino "tradicional", dificuldades que os professores enfrentam nos cotidianos escolares, bem como suas próprias formações e os materiais didáticos disponibilizados a eles e aos estudantes. Evidencia-se a necessidade de estratégias diversificadas a partir de uma prática essencialmente dialógica entre os diferentes componentes curriculares, que seja, democrática no sentido de oportunizar o protagonismo do estudante, de promover uma educação voltada à reflexão e que incentive a busca de soluções para problemas reais e locais.

O livro didático é, muitas vezes, o único material de apoio para professores, sendo determinante para as estratégias pedagógicas a serem implementadas na sala de aula. Segundo Del Pino, Loguercio e Eichler (1998, p. 67-68), quando pesquisam a confecção de materiais instrucionais alternativos e a avaliação do livro didático, afirmam que "[...] é fundamental, portanto, discutir o quanto o livro didático é definidor dos trabalhos em sala de aula, pois ele fornece todas as informações de que o professor necessita para estruturar a sua dinâmica de sala de aula". 
Considerando o livro didático, Maldaner, Zanon e Auth $(2006$, p.53) alertam que, "[...] os livros didáticos, os materiais de ensino [...] pouco mudaram nesses últimos anos. Prevalecem roteiros tradicionais de ensino que se consolidam em livros didáticos que conservam, em essência, as mesmas sequências lineares e fragmentadas de conteúdos".

Busca-se o Educar pela Pesquisa com vistas a promover a dinâmica da aprendizagem, num processo de (re) construção dos conceitos, em detrimento ao uso restrito do livro didático, do ensino conteudista e descontextualizado. Acredita-se no Educar pela Pesquisa, como princípio didático que promove movimento entre os atores do cenário da aula, professores e estudantes e desses com o conhecimento, por meio do aprender a pensar, do aprender a aprender (DEMO, 1997; GALIAZZI, 2003; MORAES, 2012) e do aprender a fazer fazendo (MATURANA; VARELA, 1995); contribuindo para uma efetiva (trans) formação qualificada dos envolvidos. Nessa pesquisa, adotou-se o Educar pela Pesquisa como princípio didático, devido a proposição de autonomia discursiva.

As Diretrizes Curriculares Nacionais para o Ensino Médio (Resolução no 2, de 30 de janeiro de 2012) legitimam a pesquisa enquanto princípio pedagógico, quando orientam as unidades escolares a considerarem em suas proposições curriculares: "a pesquisa como princípio pedagógico, possibilitando que o estudante possa ser protagonista na investigação e na busca de respostas em um processo autônomo de (re) construção de conhecimentos." (Art. 13, item III)

Nos pressupostos teóricos apresentados por Demo (1991, 1995, 1996, 1997) a pesquisa assume uma proposta metodológica em sala de aula, que objetiva desenvolver habilidades "indispensáveis em cada cidadão e trabalhador modernos: aprender a aprender e saber pensar para intervir de modo inovador" (1997, p.9), de modo a promover o trabalho coletivo, desenvolvendo a individualidade.

A pesquisa em sala de aula, segundo Moraes, Galiazzi e Ramos (2012, p. 12) atende a um princípio geral, por eles formulado:

A pesquisa em sala de aula pode ser compreendida como um movimento dialético, em espiral, que se inicia com o questionar dos estados do ser, fazer e conhecer dos participantes, construindo-se a partir disso novos argumentos que possibilitam atingir novos patamares desse ser, fazer e conhecer, estágios esses então comunicados a todos os participantes do processo.

A reflexão do princípio geral formulado pelos autores, que consiste no movimento da pesquisa iniciando-se com o questionar, o perguntar sobre o ser, o fazer, o conhecer, sobre o mundo. Para perguntar, faz-se necessária a leitura sobre o objeto questionado e a consideração de entendimentos diferentes sobre ele, o que provoca a desacomodação, a busca, o movimento da argumentação. A pesquisa no cotidiano da sala de aula exige leitura crítica do mundo e capacidade argumentativa que envolvem o domínio da linguagem. Conforme ressalta Galiazzi $(2003$, p. 87) "[...] o saber pensar e o aprender a aprender dependem e exigem capacidade comunicativa, capacidade de argumentação e de elaboração própria, passando sempre pela formulação linguística cada vez mais adequada."

Ainda ponderando a pesquisa na sala de aula, Ramos (2012, p. 31) assevera que, 
[...] o objeto da argumentação passa a ser um novo estado dos sujeitos, produto das atividades de investigação desenvolvidas, incluindo o resultado das leituras, dos experimentos, das entrevistas, dos debates e dos textos elaborados. $O$ espaço público consiste nos espaços de convivência em que predomina a própria sala de aula, sem esta ser exclusiva. A prática argumentativa é o exercício cotidiano no qual os alunos não têm apenas de ouvir, mas, ao contrário, falar, questionar, responder e argumentar.

A pesquisa proposta por Demo entende diferentes níveis. Inicialmente seria um estágio de interpretação reprodutiva, considerando fielmente o autor pesquisado; um segundo estágio, seria o da interpretação própria; no terceiro estágio, ocorreria à reconstrução; no quarto estágio, a construção e, num quinto estágio, a criação de novos paradigmas. Para todos os níveis, a linguagem, a escrita e a leitura, são pressupostos fundamentais.

A linguagem, segundo Maturana e Varela (1995), nos constitui humanos; como afirmam:

\footnotetext{
Realizamos a nós mesmos em mútuo acoplamento linguístico, não porque a linguagem nos permite dizer o que somos, mas porque somos na linguagem, num contínuo existir de mundos linguísticos e semânticos que produzimos com os outros. Encontramos a nós mesmos nesse acoplamento, não como a origem de uma referência, nem em referência a uma origem, mas sim em contínua transformação no vir-a-ser do mundo linguístico que construímos com os outros seres humanos. (MATURANA; VARELA, 1995, p. 253)
}

Para Bakhtin, o diálogo não só é relevante, como imprescindível, "ser significa comunicar-se dialogicamente. Quando termina o diálogo, tudo termina" (apud STAM, 1992, p. 72). Ao considerar, então, a linguagem e a escrita como recursos culturais, entende-se que o pensamento se constitui a partir delas, tendo implicações cognitivas. Esclarece Galiazzi (2003, p. 99) que:

\footnotetext{
$\mathrm{Na}$ educação, pela linguagem se acessa e se reconstrói o conhecimento construído no passado. Este processo está muito longe de ser apenas transmissão e recepção. As ideias não existem separadas do processo semiótico pelo qual elas são formuladas e comunicadas. Além disso, uma vez que comunicação é um processo dialógico, os significados feitos pelos falantes e ouvintes, escritores e leitores, com respeito aos enunciados, são fortemente influenciados pelo contexto no qual ocorre o discurso. Conhecer é um processo situado e dialógico.
}

Dessa forma entendemos a leitura e a escrita (processos que se ensinam e se aprendem), como habilidades fundamentais para contribuir no efetivo processo de educação em ciências, elucidando o domínio linguístico próprio da área das ciências da natureza em diferentes gêneros textuais que permeiam a sociedade, pelos quais ocorre a comunicação entre as pessoas.

No espaço escolar, as atividades que envolvem a escrita muitas vezes refletem um exercício mecânico de reprodução de ideias, como cópias e/ou respostas direcionadas às perguntas prontas, não permitindo a ampliação das ideias, a complementação e até mesmo sua reestruturação. Considera-se uma escrita, conforme Almeida, Cassiani e Oliveira (2008, p. 39), “[...] que pudesse contribuir para a constituição e expressão de pensamento no ensino escolar".

$\mathrm{Na}$ interface com a área das linguagens, buscamos o entendimento de gêneros textuais que surgem de acordo com sua função na sociedade (BRONCKART, 2003; 
MARCUSCHI, 2003; COSTA-HÜBES, 2005; LANDEIRA, 2009). Os gêneros textuais são os textos que lemos no mundo. Para alguns desses gêneros, necessitamos o domínio linguístico das diferentes ciências, como um rótulo, uma bula, uma fatura de energia, uma reportagem, uma placa de sinalização, entre outros.

O ensino da Língua Portuguesa consiste na leitura, na escrita, na interpretação, nas características formais dos textos agrupados em gêneros, mas o desafio reside em ensinar o uso social dos respectivos textos de modo a qualificar os cidadãos para lerem o mundo e escrevê-lo de forma mais solidária, criativa e consciente.

Dentre os gêneros textuais, pode-se destacar os livros e textos de divulgação científica. E sobre o conceito de divulgação científica, concorda-se com o que Gouvêa apresenta $(2015$, p.13) como "[...] uma prática social materializada em discursos gravados em diferentes suportes e que circulam nas escolas". Acreditase que essa prática social, para permanecer, precisa ser divulgada por aqueles que a acreditam como função social. E então é necessário alfabetizar os que não têm formação na área da ciência e da tecnologia como forma de consumir, utilizar e decidir sobre questões envolvendo a ciência (GOUVÊA, 2015).

Mediante a leitura e escrita de textos de divulgação científica pode-se promover a compreensão básica de termos, conhecimentos e conceitos científicos fundamentais. Inclusive, promover a compreensão da natureza das ciências, dos fatores éticos e políticos que circundam sua prática e o entendimento das relações existentes entre ciência, tecnologia, sociedade e ambiente, desde que esses aspectos sejam considerados nos objetivos de ensino.

As atividades de leitura e escrita são habilidades fundamentais, pois são elementos centrados nos processos de incorporação de conhecimento do "fazer científico". A partir do exposto, justifica-se a importância de investigar de que forma "a pesquisa contemplando a escrita e a leitura de livros e textos de divulgação científica", promovem aprendizagem, ou seja, contribuem para a construção, ampliação e aprofundamento de conceitos científicos por estudantes do Ensino Fundamental e Médio.

A relevância da investigação acerca da articulação entre a pesquisa, a escrita e a leitura de livros e textos de divulgação científica, se dá pela possibilidade de apontar valorizações e/ou reestruturações nas propostas pedagógicas. Além disso, a necessidade de investigação da prática docente e a qualificação dos professores por meio da formação inicial e continuada, contribui para a (re)elaboração de currículos reais, aplicados e instigantes para o processo de ensino e de aprendizagem.

Nesse viés de discussões, pergunta-se: o que se lê nas aulas de Ciências da Natureza? Para que essa leitura é utilizada? A realidade e a cultura do local onde a escola está inserida são consideradas e valorizadas? O que se escreve nas aulas de ciências da natureza, se cria ou se copia? É possível ensinar e aprender ciências da natureza por meio de gêneros textuais? Quais livros e textos de divulgação científica utilizar para construir conceitos científicos? Quando e como utilizá-los? Estas foram algumas questões que motivaram o planejamento e a execução de atividades que são apresentadas, culminando na questão problema: de que forma a articulação entre a leitura dos livros e textos de divulgação científica podem 
promover a (re) construção de conceitos científicos por estudantes do Ensino Fundamental e Médio?

O presente trabalho pretende apresentar as práticas pedagógicas envolvendo livros e textos de divulgação científica, por meio da leitura, da escrita e, da pesquisa, elucidando as marcas de aprendizagem dos estudantes do Ensino Fundamental e Médio, ao longo de quatro anos letivos, de 2014 a 2017.

\section{CAMINHOS PERCORRIDOS}

A metodologia adotada nesta pesquisa parte das práticas de leitura de livros e textos de divulgação científica no ensino das ciências da natureza como estratégia dialógica para abordagem dos conteúdos conceituais da área. É neste sentido, que se desenha o caminho percorrido para a realização desta pesquisa, que utilizou como estratégia de investigação: o estudo de caso. André (2008, p. 31) salienta que o estudo de caso deve ser usado quando: “[...] (1) há interesse em conhecer uma instância em particular (2) pretende-se compreender profundamente essa instância particular em sua complexidade e totalidade; e (3) busca-se retratar o dinamismo de uma situação numa forma muito próxima do seu acontecer natural.

Os procedimentos que delinearam o caminho percorrido foram: inicialmente a leitura compartilhada em sala de aula, de modo a emergir coletivamente aspectos interessantes apontados pelos estudantes, nas aulas de Ciências, no Ensino Fundamental, Química e Biologia, no Ensino Médio.

Ao longo dos quatro anos, foram apresentadas diferentes leituras para 23 estudantes que compunham, em 2014, uma turma de 9o ano (EFII); ao longo do Ensino Médio, a esses mesmos estudantes foram sendo apresentadas leituras diferentes, com estratégias didáticas diferentes, até o momento, em 2017, compondo uma turma de 3 o ano (EM), com 19 estudantes. Dos 23 estudantes iniciais, houve a saída de 6 estudantes e a entrada de 2 novos estudantes na turma, desde o 10 ano (EM), em 2015.

Os livros e textos de divulgação científica, utilizados ao longo dos quatro anos, estão explicitados no quadro 1: A colher que desaparece - Sam Kean; Da Química à Microbiologia - Louis Pasteur - Sabrina Rodrigues; Ei, tem alguém aí - Jostein Gaarder; Os cientistas e seus experimentos de Arroba - Mike Goldsmith e 50 plantas que mudaram o rumo da história Bill Laws (2013).

Quadro 1 - Livros de divulgação lidos em sala de aula

\begin{tabular}{|c|c|}
\hline Livro & Síntese \\
\hline $\begin{array}{c}\text { A colher que desaparece } \\
\text { e outras histórias reais de } \\
\text { loucura, amor e morte a } \\
\text { partir dos elementos } \\
\text { químicos - Kean (2007) }\end{array}$ & $\begin{array}{c}\text { A colher que desaparece apresenta as disputas políticas, } \\
\text { guerras, descobertas de cientistas que estavam } \\
\text { comprometidos em contribuir com o desenvolvimento do } \\
\text { conhecimento, envolvendo os elementos da tabela } \\
\text { periódica. }\end{array}$ \\
\hline $\begin{array}{c}\text { Os cientistas e seus } \\
\text { experimentos de arromba } \\
\text { - Goldsmith (2007) }\end{array}$ & $\begin{array}{c}\text { A ciência é parte fundamental do nosso dia-a-dia - já } \\
\text { imaginou como seria a vida sem carro, telefone, } \\
\text { computador, pasta de dente?... E sem algumas mentes } \\
\text { descobertas, revolucionaram o mundo? Pois é, mesmo }\end{array}$ \\
\hline
\end{tabular}




\begin{tabular}{|c|c|}
\hline & $\begin{array}{c}\text { depois de mortos, os cientistas ainda são como caixinhas } \\
\text { de surpresas - e os nove que este livro traz são } \\
\text { particularmente incríveis. }\end{array}$ \\
\hline Ei, tem alguém aí! & $\begin{array}{c}\text { Esta é a história de um menino de oito anos que vai } \\
\text { ganhar um irmãozinho. Enquanto espera os pais voltarem } \\
\text { da maternidade, ele recebe a visita de Mika, uma espécie } \\
\text { de pequeno príncipe que parece de outro planeta. Os } \\
\text { dois são muito diferentes, mas são muito parecidos } \\
\text { também. Passam 24 horas juntos e conversam sobre } \\
\text { temas como a origem da vida, os princípios da evolução e } \\
\text { a extinção dos dinossauros. Quando Mika vai embora e os } \\
\text { pais voltam com o bebê, o menino sabe, de algum modo, } \\
\text { que sua casa tem espaço para um novo habitante. }\end{array}$ \\
\hline $\begin{array}{c}\text { Louis Pasteur: da química } \\
\text { à microbiologia. } \\
\text { Rodrigues (2015) }\end{array}$ & $\begin{array}{c}\text { Baseado em estudos acadêmicos realizados pela autora } \\
\text { em sua formação como historiadora da ciência, este livro } \\
\text { aborda e analisa os fatores e indícios encontrados por } \\
\text { Pasteur em seus estudos de cristalografia que o levaram } \\
\text { até a teoria microbiana das doenças. }\end{array}$ \\
\hline $\begin{array}{c}\text { O autor apresenta características das plantas que } \\
\text { o plantas que mudaram } \\
\text { Laws (2013) }\end{array}$ & $\begin{array}{c}\text { marcaram a história da humanidade e que estão no } \\
\text { cotidiano das pessoas de diferentes culturas; } \\
\text { relacionando o contexto histórico e social de cada uma } \\
\text { delas. }\end{array}$ \\
\hline
\end{tabular}

Fonte: Adaptado pelos autores a partir dos livros originais (2017).

Logo após as leituras foram propostas estratégias didáticas, como: rodas de conversas, registros individuais por meio de diários de leitura; apresentação de seminários, elaboração e realização de experimentos, representação de imagens (desenhos ou colagens) e representação teatral. Tais itens exemplificam as diferentes estratégias didáticas propostas.

Figura 1 - Estratégia Didática para o livro A colher que desaparece: representação e montagem da tabela periódica.

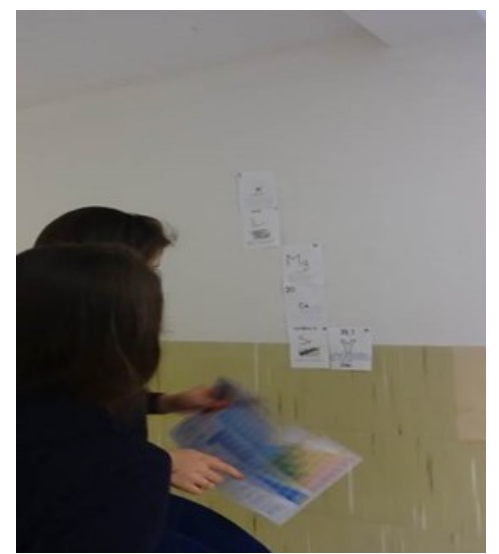

Fonte: Autoria própria (2015). 
Figura 2 - Estratégia Didática para o livro A colher que desaparece: representação e montagem da tabela periódica.

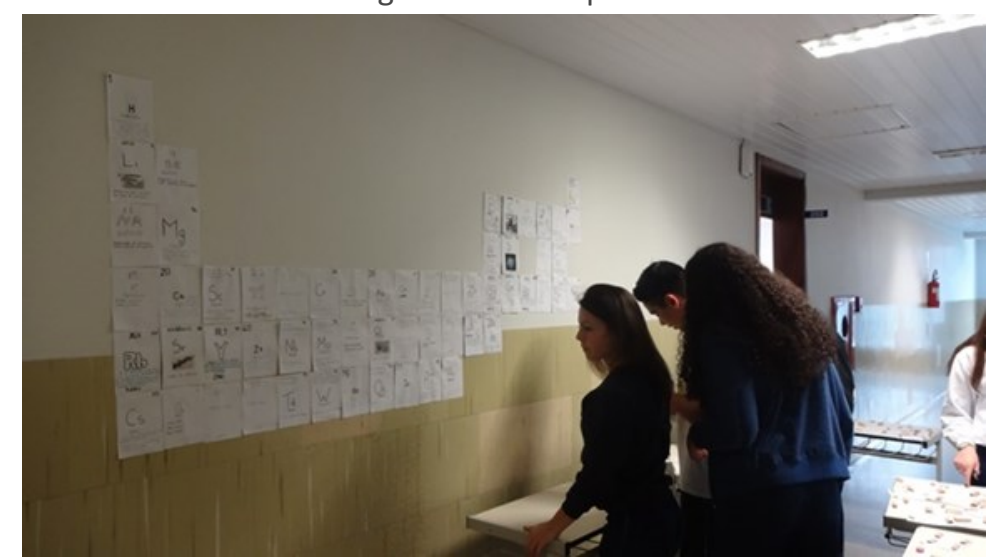

Fonte: Autoria própria (2015).

Figura 3 - Estratégia Didática para o livro Louis Pasteur da química a microbiologia: representação e confecção dos eixos que fundamentam a nova historiografia da ciência.

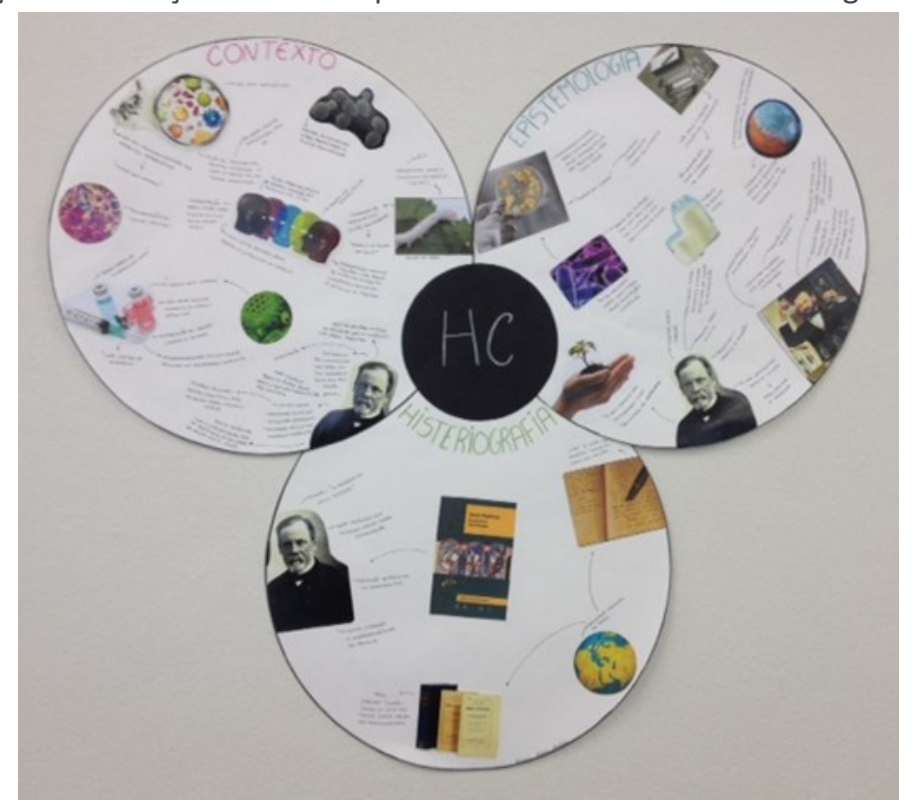

Fonte: Autoria própria (2017).

Em 2017, os estudantes que se encontravam no 3 o ano (EM) foram questionados em grupo quanto às memórias/marcas de aprendizagem deixadas pelas práticas de leituras, por meio de um questionário, composto por três perguntas abertas. As questões propostas foram: Quais leituras foram oportunizadas nas aulas de Ciências, Biologia e Química? De que forma essas práticas de leitura favorecem o seu aprendizado? As leituras realizadas o motivaram a buscar outras leituras, escritas e pesquisas? Quais?

A partir das respostas dos estudantes foi possível articular duas categorias de análise: marcas de aprendizagem conceitual proporcionadas pelas leituras e dinâmicas de pesquisa promovidas pelas leituras. 


\title{
AS MARCAS DE APRENDIZAGEM CONCEITUAL PROPORCIONADAS PELAS LEITURAS
}

Considerando as respostas das questões propostas aos estudantes após as práticas de leitura, percebeu-se que os livros e textos que mencionaram foram:

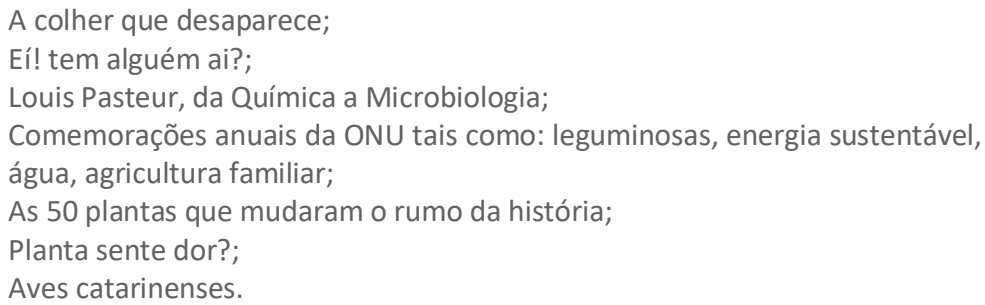

Essas leituras produziram marcas de aprendizagem, que aqui têm o sentido do que ficou, do que permaneceu, isto é, são as vivências proporcionadas por essas práticas de leitura. Pode-se perceber nas respostas 1 dos estudantes R1, R5 e R6 que versaram sobre os conteúdos conceituais relacionados com os fenômenos lidos e discutidos, indicando as marcas conceituais. Moraes, Ramos e Galiazzi (2007, p. 199) salientam que "[...] a leitura ajuda a criar espaço de interação com uma comunidade de especialistas nos diferentes temas tratados, possibilitando questionar o conhecimento inicial do senso comum no sentido de uma aproximação ao científico [...]". Os conceitos expressam significados que indicam conhecimentos para além da sala de aula, evidenciados nos trechos destacados em negrito:

\footnotetext{
"Introdução à tabela periódica; base sobre átomos; conhecimento sobre micro-organismos e a importância dos mesmos; estudo aprofundado sobre o reino plantae, monera, protista, fungi, metazoa" (R1).
}

"Aprendemos sobre diversas espécies de plantas que formam a vegetação do nosso planeta, aprendemos suas características, suas composições e a forma de organização em nosso planeta" (R5)

\begin{abstract}
"Tivemos uma ampliação em nossa perspectiva de ciências, conhecemos diversos ambientes de áreas diferentes, como alimentação, anatomia, agricultura, conceitos físicos e químicos de materiais que usamos no cotidiano. Aprendemos mais sobre as espécies vegetais que transformaram a vida no nosso planeta, o nome científico da planta, suas características físicas e seus principais usos, seja ele medicinal, comestível ou prático. E ainda um pouco da história socioeconômica, política e agrícola que constituem um olhar sobre as plantas sem as quais o homem não consegue viver" (R6).
\end{abstract}

Já as respostas R2, R3 e R7 mencionaram os livros lidos reconhecendo os conteúdos conceituais discutidos, as explicações, as provocações, as proposições que as leituras movimentaram no processo de ensino e aprendizagem. A resposta R7 aponta um aspecto importante que a leituras destes textos proporcionaram: o contato com os assuntos abordados, como sendo o primeiro e, quem sabe, o único momento em que o estudante teve a oportunidade de conhecer e discutir aquele assunto. Isso nos mostra a relevância da escolha e do planejamento dessas práticas 
de leitura pelo professor, evidenciando a ideia de Chartier (1998, p. 77), quando enfatiza que "A leitura é sempre apropriação, invenção, produção de significados".

Todas as obras trouxeram conhecimentos através de grandes experimentos e curiosidades, como foi a de Louis Pasteur, através desse livro conhecemos a história da microbiologia na fermentação, cristalografia, etc. Confeccionamos uma tabela periódica através do livro A Colher que Desaparece, fazendo assim, que conhecêssemos mais sobre as substâncias da tabela (R2).

Os livros fizeram-nos interessarmos pelos cientistas e seus experimentos, além de nos ambientizar em suas difíceis épocas onde reinava a ignorância e assim incentivar-nos a buscar mais sobre, e saber mais sobre biologia e a ciência em geral, como por exemplo, a fermentação de Louis Pasteur e, o livro "A colher que desaparece" onde podemos nos aprofundar mais em alguns elementos da tabela periódica e assim, fazendo alguns experimentos que nos eram propostos, melhorando o nosso conhecimento sobre eles (R3).

Cada um apresenta de maneira única os conteúdos abordados, despertando interesse e a curiosidade pelos assuntos. Também são muitas vezes uma introdução ao assunto tratado, já que em alguns casos o primeiro contato com o tema da leitura foi justamente a leitura (R7).

A resposta R4 atenta para a contextualização e a interdisciplinaridade, salientando a relação entre aquilo que se vivência e a capacidade do desenvolvimento da argumentação por meio das leituras e discussões: "O conhecimento mais abrangente sobre o assunto podendo relacioná-lo com outras áreas e situações do dia a dia em nosso cotidiano e tendo argumentos convincentes para falar sobre" (R4).

É evidente em algumas respostas, como na R7, a compreensão do tema abordado a partir das diferentes estratégias pedagógicas, nas quais a leitura ora era a introdução do tema, ora era a sua complementação, destacando a importância do planejamento do professor. Conforme Kleiman (2013, p. 15), “A compreensão de um texto é um processo que se caracteriza pela utilização de conhecimento prévio: o leitor utiliza na leitura o que ele já sabe o conhecimento adquirido ao longo de sua vida".

\section{DINÂMICAS DE PESQUISA PROMOVIDAS PELAS LEITURAS.}

Outro aspecto evidenciado nas respostas foi a forma como se deu a pesquisa posteriormente as leituras, nas aulas curriculares. Neste sentido Moraes, Ramos e Galiazzi (2007, p. 198) afirmam que "leituras são modos de estabelecer conversas com cientistas sobre os mais diversificados temas, leituras feitas não de forma isolada, mas em combinação estreita com a fala e a escrita". Alguns estudantes relacionaram outras leituras e pesquisas que foram movimentadas a partir das leituras iniciais, nas respostas R1 e R7. Essas pesquisas visavam um aprofundamento e ampliação do conhecimento indicados pelos estudantes. 
"[...] interesse por revistas que abordam alguns dos assuntos, com o intuito de aprofundamento e ampliação do conhecimento, em periódicos como SUPERINTERESSANTE e Mundo Estranho. Além de claro, as leituras que geraram pesquisas, que por suas vezes foram muito marcantes, como o caso da leitura do Ano Internacional da Agricultura Familiar, que está vivo na memória de todos os alunos que participaram da visita a propriedade familiar produtora de milho" (R7).

As respostas R2, R3 e R6 mostram o interesse e aprofundamento nos temas lidos e discutidos. Percebe-se que na R3 o estudante movimentou vários assuntos e interesses por ele relacionados, demonstrando a importância das leituras.

“[...] Pesquisamos a respeito de energia (que foi estudada na metade do terceiro trimestre), que revisamos em física no primeiro ano, e usamos livrosbase do ano anterior para introduzirmo-nos à física" (R6).

Mesmo não despertando interesse, para alguns estudantes, as leituras promoveram compreensões sobre o assunto estudado: "[...], pois mesmo aprendendo em sala de aula não despertou um interesse pessoal no assunto abordado, porém com as leituras conseguimos compreender e abranger nosso conhecimento sobre tal assunto" (R5).

Podemos considerar após todo esse tempo e espaços oportunizados de leituras, que os estudantes foram desafiados a ampliarem os significados de diversos conceitos por meio dos diálogos com outros autores e da apropriação desses significados mediante a pesquisa.

A partir dos pressupostos apresentados até aqui, acreditamos que "[...] os estudantes que têm subjacentes os princípios do educar pela pesquisa, podem aprender uma proposta com qualidade política, pois os professores centram seus objetivos na possibilidade de os alunos aprenderem a aprender" (GALIAZZI, 2003, p. 227).

\section{CONSIDERAÇÕES FINAIS}

As leituras propostas proporcionaram marcas de aprendizagem, que evidenciadas pelos estudantes demonstraram aprimoramento na realização das pesquisas posteriores. Possibilitou aprofundamento e ampliação dos 
conhecimentos e olhares mais pontuais para os conteúdos conceituais das ciências. Nos processos citados, as ações propostas pelo professor, no que tange o ensinar e o aprender das habilidades de leitura, individual e coletiva, e de escrita, expressam a relevância dessas práticas em sala de aula. Moraes (2012, p. 101) reitera que "[...] os princípios do educar pela pesquisa possibilita aprendizagem de modos de aprender por conta própria, viabilizando o aprender a aprender, base da competência e autonomia".

Torna-se evidente a importância de o professor ser pesquisador de sua prática docente, de planejar ações pedagógicas que lhe permitam acompanhar o desenvolvimento cognitivo dos estudantes. Acreditamos que "[...] a construção dos conhecimentos, dando-se com um envolvimento ativo dos sujeitos, em parceria com professor e colegas, possibilita aprendizagens significativas e duradouras" (MORAES, 2012, p. 101).

As diferentes estratégias didáticas compuseram diferentes episódios escolares. Porém, em todos a leitura coletiva foi privilegiada, o que permitiu a construção de sentidos para os estudantes.

Mediante as práticas de leitura proporcionadas e evidenciadas nas falas dos estudantes acreditamos na dinâmica de uma reconstrução permanente dos conhecimentos, tanto individualmente quanto no coletivo, propiciando uma nova compreensão do aprender. 


\title{
The marks of learning through research, writing and reading of books of scientific divulgation: a possibility for the classroom
}

\begin{abstract}
The present work displays the reading practices carried out during four years with 23 students, between 2014 and 2017. Throughout the High School, these same students were presented to different readings, with different didactic strategies. After the proposed readings the following didactic strategies were performed: conversation circles, individual records by reading diaries; presentation of seminars, experiment design and conduction, images representation (drawings or collages) and theatrical performance. In 2017, students from the 3rd year of high school were asked about the memories/marks of learning left by the reading practices, using a questionnaire. From the students answers it was possible to articulate two categories of analysis: conceptual learning marks and research dynamics. The proposed readings provided learning marks evidenced by the students and they stimulated the subsequent researches performed during the curricular classes, enabling a deepening and amplification of the knowledge and more specific perspectives for the conceptual contents of sciences. In this process, the actions proposed by the teacher, regarding the teaching and learning of reading skills, individual and collective, and writing, express the relevance of these practices in the classroom.
\end{abstract}

KEY WORDS: Reading Practice. Writing. Search. Books of scientific divulgation. 
NOTA

1. Identificamos as respostas dos estudantes como R1, R2, R3, sucessivamente.

\section{REFERÊNCIAS}

ALMEIDA, M. J. P. M.; CASSIANI, S.; OLIVEIRA, O. B. Leitura e escrita em aulas de ciências: luz, calor e fotossíntese nas mediações escolares. Florianópolis: Letras Contemporâneas, 2008.

ANDRÉ, M. E. D. A. de. Estudo de caso em pesquisa e avaliação educacional. 3ed. Brasília: Líber Licro Editora, 2008.

ARAÚJO, D. L. O que é (e como faz) sequência didática? Entrepalavras, ano 3, v. 3, n. 1, p. $322-334,2013$.

BAKHTIN, M. A interação verbal. IN: BAKHTIN, M. Marxismo e Filosofia da linguagem. 6. ed. São Paulo: Hucitec, 1992.

Os gêneros do discurso. IN: BAKHTIN, M. Estética da Criação Verbal. 3. ed. São Paulo: Martins Fontes, 2000.

BEZERRA, M. A. Por que cartas de leitor na sala de aula?. IN: DIONÍSIO, Â. P.; MACHADO, A. R.; BEZERRA, M. A. Gêneros textuais \& ensino. 2. ed. Rio de Janeiro: Lucerna, 2003.

BRONCKART, J. P. Atividade de linguagem, texto e discurso. São Paulo: EDUC, 2003.

Atividade de linguagem, discurso e desenvolvimento humano.

Campinas, SP: Mercado das Letras, 2006.

CACHAPUZ, A.; GIL-PEREZ, D.; CARVALHO, A. M. P.; PRAIA, J.; VILCHES, A. A Necessária renovação do ensino das ciências. 2. ed. São Paulo: Cortez, 2011.

CHARTIER, R. A aventura do livro do leitor ao navegador. São Paulo: Editora da UNESP e Imprensa Oficial, 1998.

CONSELHO NACIONAL DE EDUCAÇÃO. Define Diretrizes Curriculares Nacionais Gerais para Educação Básica. Resolução n. 4, de 13 de julho de 2010. Diário Oficial da União, Brasília, 14 de julho de 2010, Seção 1, p. 824. 
CONSELHO NACIONAL DE EDUCAÇÃO. Define Diretrizes Curriculares Nacionais para o Ensino Médio. Resolução n. 2, de 30 de janeiro de 2012. Diário Oficial da União, Brasília, 31 de janeiro de 2012, Seção 1, p. 20.

CORDEIRO, G. S. Escrevendo narrativas de aventuras de viagens na 3a série do ensino fundamental. IN: Anais da III Conferência de Pesquisa Sócio-cultural. 2000, $1-18 p$.

COSTA-HÜBES, T. C. Produção escrita de textos: atividades didáticas de interação social. Ponta Grossa: UEPG/CEFORTEC, 2005.

DEMO, P. Pesquisa e construção de conhecimento: metodologia científica no caminho de Habermas. Rio de Janeiro: Tempo Brasileiro, 1997.

Educar pela pesquisa. Campinas: Autores Associados, 1996.

Educação e qualidade. 2. ed. Campinas: Papirus, 1995.

Pesquisa: princípio científico e educativo. São Paulo: Cortez, 1991.

DEL PINO, J. C.; EICHLER, M.; LOGUERCIO, R. Q. Avaliação do livro Didático e confecção de materiais Instrucional Alternativos como estratégia de formação Continuada de Professores. In: CONGRESO IBEROAMERICANO DE EDUCACIÓN EN CIENCIAS EXPERIMENTALES, 1998, La Serena. Libro de Actas del Congreso Iberoamericano de Educación en Ciencias Experimentales, 1998. p. 67-69.

DOLZ, J.; NOVERRAZ, M.; SCHNEUWLY, B. Sequências didáticas para o oral e a escrita: apresentação de um procedimento. IN: DOLZ, J.; SCHNEUWLY, B. Gêneros orais e escritos na escola. Campinas, SP: Mercado de Letras, 2004.

FREITAS, F. I. O. Ensinando a argumentação no Ensino Médio a partir do trabalho com artigos de opinião. Campina Grande, 2006, 178p. Dissertação (Mestrado em Linguagem e Ensino) Universidade Federal de Campina Grande, 2006.

GAARDER, Jostein. Ei! Tem alguém aí? São Paulo: Companhia das Letrinhas, 1997.

GAIO, R. Metodologia da Pesquisa e Produção do Conhecimento. Petrópolis: Editora Vozes, 2008.

GALIAZZI, M. C. Educar pela pesquisa: ambiente de formação de professores de 
GOLDSMITH, Mike. Os cientistas e seus experimentos de arromba. São Paulo: Companhia das Letras, 2007.

GONÇALVES, L. G. Análise linguística: influência no ensino de escrita de alunos do ensino fundamental II. Campo Grande, 2012. Monografia (Conclusão de Curso Licenciatura em Letras) Universidade Federal de Campo Grande, 2012.

KEAN, Sam. A colher que desaparece: e outras histórias reais de loucura, amor e morte a partir dos elementos químicos. Rio de Janeiro: Zahar, 2011.

KLEIMAN, A. Texto e leitor: Aspectos cognitivos da leitura. Campinas, SP: Pontes Editores, 2013.

LANDEIRA, J. L. Gêneros textuais na sala de aula: entre modas e realidades. Na Ponta do Lápis, ano V, n. 11, p. 4-7, 2009.

LAWS, B. 50 Plantas que mudaram o rumo da história. Rio de Janeiro: Sextante, 2013.

LÜDKE, M.; ANDRÉ, M. E. Pesquisa em Educação: abordagens qualitativas. São Paulo: EDU Editora, 1986.

MALDANER, A. O.; ZANON, L. B.; AUTH, A. M. Pesquisa sobre Educação em Ciências e formação de professores. In: SANTOS, F. M. T.; GRECA, I. M. (Org.). A pesquisa em Ensino de Ciências no Brasil e suas Metodologias. Ijuí: Editora ljuí, 2006.

MARCUSCHI, L. A. Gêneros Textuais: definição e funcionalidade. IN: DIONÍSIO, Â. P.; MACHADO, A. R.; BEZERRA, M. A. Gêneros textuais \& ensino. 2. ed. Rio de Janeiro: Lucerna, 2003.

MAtURANA, R. H.; VARELA, F. A árvore do conhecimento. Campinas: Psy II, 1995.

MORAES, R. Educar pela Pesquisa: exercício de apender a aprender. In: MORAES, R.; LIMA, V. M. R. Pesquisa em sala de aula: tendências para a educação em novos tempos. 3. ed. Porto Alegre: EDIPUCRS, 2012.

MORAES, R.; GALIAZZI, M. C. Análise Textual Discursiva. Ijuí: Editora Unijuí, 2007.

MORAES, R.; RAMOS, M. V. G.; GALIAZZI, M. do C. Aprender Química: promovendo excursões em discursos da Química. In: ZANON, L. B.; MALDANER, O. A.(Org.) Fundamentos e Propostas de Ensino de Química para a Educação básica no Brasil, ljuí: Ed. Unijuí, 2007. 
MORAES, R.; GALIAZZI, M. C.; RAMOS, M. G. Pesquisa em Sala de Aula: fundamentos e pressupostos. In: MORAES, R.; LIMA, V. M. R. Pesquisa em sala de aula: tendências para a educação em novos tempos. 3. ed. Porto Alegre:

EDIPUCRS, 2012.

RAMOS, M. G. Educar pela Pesquisa é Educar para a Argumentação. In: MORAES, R.; LIMA, V. M. R. Pesquisa em sala de aula: tendências para a educação em novos tempos. 3. ed. Porto Alegre: EDIPUCRS, 2012.

RODRIGUÊS, S. Louis Pasteur: da química à microbiologia. São Paulo: Livraria Editora da Física, 2015.

SACRISTÁN, J. G.; GÓMEZ, A. I. P. Compreender e Transformar o Ensino. Porto Alegre: Artes Médicas Ed., 2000.

SCHWARTZ, S. De Objetos a Sujeitos da Relação Pedagógica: a pesquisa na sala de aula. In: MORAES, R.; LIMA, V. M. R. Pesquisa em sala de aula: tendências para a educação em novos tempos. 3. ed. Porto Alegre: EDIPUCRS, 2012.

SILVA, J. D. Uma abordagem cognitiva ao planejamento estratégico do desenvolvimento sustentável. Florianópolis, 1998, 239p. Tese (Doutorado em Engenharia de Produção) Universidade Federal de Santa Catarina, 1998.

STAM, R. Bakhtin: da teoria literária à cultura de massa. São Paulo: Ática, 1992.

VYGOTSKY, L. S. A Formação Social da Mente. São Paulo: Martins Fontes, 1998.

Recebido: 19 dez. 2017

Aprovado: 19 jul. 2018

DOI: $10.3895 /$ actio.v3n2.7540

Como citar:

LUCA, A. G.; SANTOS, S. A.; DEL PINO, J. C.; PIZZATO, M. C. As marcas de aprendizagem por meio da pesquisa, da escrita e da leitura de livros de divulgação científica: uma possibilidade para a sala de aula. ACTIO, Curitiba, v. 3, n. 2, p. 116-132, mai./ago. 2018. Disponível em: <https://periodicos.utfpr.edu.br/actio>. Acesso em: XXX

Correspondência:

Anelise Grünfeld de Luca

Rua Anita Garibaldi, n. 704 - ap. 203, Anita Garibaldi, Joinville, SC, Brasil. CEP: 89203-300

Direito autoral: Este artigo está licenciado sob os termos da Licença Creative Commons-Atribuição 4.0

Internacional.

(c) (i) 